\title{
Action Research on Sensory Integration Training Integrated into Children's Sports Activities
}

\author{
Ying Zhang ${ }^{a}$, Fei Wang ${ }^{b}$, Jun Yang ${ }^{c}$ \\ College of Education and Sports, Bohai University, Jinzhou, 121013, China \\ a47086132@qq.com, b839680698@qq.com, c444530141@qq.com
}

\begin{abstract}
Keywords: sensory integration training; children's sports activities; action research; development strategy
\end{abstract}

\begin{abstract}
This study combines the related disciplines of sports science, physiology, education, developmental psychology, sports medicine, curriculum teaching theory and the theory of children development, the significance of sensory integration training into children's sports activities are elaborated, and through the comprehensive training of the senses in the action research department of Liaoning province city kindergarten and early education institutions, targeted the effective implementation of sensory integration training in children's physical activity in the development strategy. Through this new type of education method, the fully develop the early childhood sports potential, improve the quality of children, promote children's physical and mental harmony development. Comprehensively carry out the reform and innovation of the children's sports, promote the formation of standardized, standard child care sports system and sports training mode, and promote the vigorous development of China's sports health.
\end{abstract}

\section{Introduction}

Early childhood is a critical period for the development of physical and mental development, is also the key to establish a good material foundation, the early childhood behavior habits, personality formation and physical fitness are the basis of the development of people's life, and sports are the objective needs of their physical exercise, achieve their physical development and the development of the balance of sports [1]. Therefore, through physical exercise, enhance physical fitness, cultivate sentiment, cultivate good psychological quality and social adaptability, shaping the system of children's physical health has become an urgent need for the development of modern society. Sensory integration training is a kind of sports training correction method, it is through specific sports equipment for children's feeling and sports ability for a purpose, have a plan, targeted training, is a kind of children are willing to participate in the sports games [2]. Therefore, it has become a topic of concern to integrate sensory integration training into children's physical activity and to carry out the action research on sensory integration training to improve children's physical function and mental ability.

This study further implement the "national long-term education reform and development plan (2010 - 2020)" and "the State Council on the current development of pre-school education", in depth understanding of the current situation and existing problems in the development of children's sports activities, and put forward that the introduction of physical activity in children can improve the physical function and mental ability of the comprehensive training content. To enrich the related theory of preschool education in our country and promote the practice of preschool physical education, provide scientific basis for the decision-making of the competent departments of the preschool education, and provide a theoretical reference for the development and utilization of the effective sports resources for young children.

Sensory integration training can be described as a kind of new method of kindergarten children's education, which is a kind of function of physical training, recreation, development of children's intelligence and correct behavior deviation. In this study, we choose different areas of Liaoning province of kindergarten and parent child institutions as the object of action research in Dalian city, Anshan city, Jinzhou city, Shenyang city, Dandong city, through the investigation of the resources 
development of the children's sports activities in province of Liaoning, the main factors that influence the development of children's sports activities are explored. At the same time, based on the comprehensive training of the senses as a breakthrough in reform and innovation of children's sports activities, select the action research in part city of the province of Liaoning kindergarten and early education institutions of sensory integration training on children, follow the "action research plan establishment - action research program -" reflecting on the process of action research, the formation of scientific development concept, develop training practical training objectives, with reasonable and effective training methods, establish the all-round development of children as the main body of the training evaluation system. In the end, the changes of physiological and psychological changes were detected and compared before and after training, explore the important role of improving children's physical function and mental ability, and put forward the development strategy of the comprehensive training of kindergarten based on the sustainable development of sustainable development. To construct the sustainable development of children's physical education concept, enrich the contents of sports activities, achieve the content of children's sports activities to set up a reasonable, form the characteristics of kindergarten and parent child sports resources, promote children's physical function and mental ability, and provide practical basis and reference value for the development of children's education workers.

\section{Important Significance on Sensory Integration Training Integrated into Children's Sports Activities}

Implementation of the "kindergarten education guidelines (Trial)" needs, children are the country's future, the nation's hope. Children's health, and lively growth can not deny that the whole country as well as the country's booming development of the future. The Ministry of education in the "twenty-first century education revitalization action plan" in a text, stressed that:"the implementation of quality education, we must start from the early childhood education, with scientific methods and the development of children's intelligence, training of children's health, good habits, lively and cheerful personality and desire for knowledge" [3]. In july 2001 the ministry of education promulgated the "guidelines for kindergarten education (trial)" clearly pointed out:"the protection of children's life and the promotion of child health" should be the primary task of kindergarten, promote the development of children's physical development and function of the coordinated development, enhance physical fitness, and enhance the living habits and interest in sports activities, and develop the basic coordination and flexibility, improve the adaptability of the environment. Sensory integration training helps to promote the development of the brain, the development of intellectual potential, and can promote the development of children's action, physical fitness, body coordination, attention, understanding, memory, creativity, performance, interpersonal skills, language expression ability and so on. Therefore, the integration of sensory integration training into the kindergarten sports activities is to thoroughly implement the "kindergarten education guidelines (trial)".

Break through the bottleneck of the development of the traditional children's education "heavy and light body". With the rapid development of science and technology, social life and social consciousness, as the initial stage of lifelong education, early childhood education has aroused the concern of the society.

The mental development of children, the physical quality of children are more and more attention, and the children's physical education is from the past. However, in reality, there are still a single development of intellectual education, the lack of practical ability to control, kindergarten education primary school, "heavy intelligence light body" of the traditional education ideas, seriously affect the mental health of young children, the children's physical and health conditions are not happy [5]. This research puts forward the concept of sensory integration training into the children's sports activities, which aims to realize the comprehensive development of children's physical health, cognitive development, and social and social fields.

Sensory integration training is the foundation for building a new type of health care model for young children. With the development of children's physical and mental development, the theory of 
sensory integration has gradually spread to the world, from the early "sensory integration treatment" has gradually changed into "sensory integration education activities", the social public has a lot of recognition for their utility. Based on this, sensory integration training knowledge is essential for the healthy development of children. Gradually form a new type of children's sports health model, integrat into the process of early childhood education, penetrate into the side of everyone, the concept of "sensory integration training" has a radial expansion, in order to build a new type of child health care model, and ultimately achieve the purpose of lifelong physical health development of children's physical education.

Sensory integration training is an effective method to improve the physical function and mental ability of children. Each child has a huge physical and psychological potential, sensory integration training is an effective means to improve the physical function and mental ability of children. Therefore, through sensory integration training for children's physical and mental potential to get the most of the excavation, so that children develop healthier, more intelligent, is the common expectation of family and society. Children's sensory integration ability is the function of the brain itself, but the development of this function, but also need to rely on the environment of the stimulus and the requirements of excitation. The sensory integration ability of most children develops in the process of games, sports and leisure activities. Therefore, the integration of sensory integration training into the children's sports activities can not only develop and improve the children's sensory acuity and sensory integration ability, but also help to promote the comprehensive development of their behavior, and can make the children's potential to be effectively developed.

The platform of sensory integration train for children's innovative education. Children's sensory integration training is the product of innovative education, is the basic premise of children's health and long-term development, health theory combined with the practice of health care as the basic means, improve the physical quality and the development of children's fitness for the fundamental purpose, for the children's physical education and children's fitness to find the best combination of training. This research combines the knowledge of sports physiology, sports medicine, sports measurement and evaluation, put forward the content of sensory integration training in children's sports activities, which is a platform for the full embodiment of the concept of innovation education for young children, for the children's sports activities in front of the new attitude.

\section{Action Research on Sensory Integration Training Integrated into Children's Sports Activities}

Action research is a plan to have the step of the teaching practice in the problem caused by the teacher or the researchers work together, research and action is method for solving the practical problems for the purpose of solving the practical problems in the research [7]. Sensory integration training is a new way of children's education, which is a new way of physical education, entertainment, development of children's intelligence and correct behavior deviation. It is not only beneficial to improve the sensitivity and sensory integration ability, but also help to improve children's thinking and explain the comprehensive and integrated level. Therefore, it is suitable for the kindergarten and parent organization. The kindergarten and parent organization have the feasibility to carry out the sensory integration training: to improve the physical function and mental ability of the children, and to reflect the needs of the development of children's personality, the need of modern children's physical education, the needs of the reform, the need to enrich the content of children's sports activities, and the need for teachers' professional development.

Based on actual situation, this research selects the kindergarten and parent child in Shenyang, Jinzhou, Anshan, Dandong, Dalian and other areas in province of Liaoning as the case study object, follow the cycle of "planning a action to observe a reflection", an action research on improving the physical function and mental ability of children with sensory integrative training, and put forward the Countermeasures for the development of the scientific and reasonable. The action research process is divided into: action research plan establishment, action research project implementation and action research reflection three part, the concrete embodiment is the formation of scientific development training idea, the formulation concrete feasible training target, with the reasonable effective training method, the establishment takes the young child's heart full development as the 
main body training evaluation system and so on. The research object of action research in different regions of province of Liaoning 3 to 6 years old healthy children, including 3 year old male child 20, female 20; 4 year old male child 20; 5 year old group male 20, female 20; 6 year old male child 20, 8 children, a total of 160 children, achieve the expected results. Before the start of action research respectively on the participation of sensory integration training of child care teaching before and after physical quality-Tennis throw far, standing long jump, sit and reach, 10 meter running, walking the balance beam completion time, continuously jumping and other items for testing. In the aspect of mental ability, the psychological test of the children's attention, comprehension, memory and language expression are detected before and after the experiment.

\section{Development Strategy on Sensory Integration Training Integrated into Children's Sports Activities}

Establish correct values of children's sports. In twenty-first century, the children should be both independent and spontaneous, but also have a healthy development of social, can care about themselves, care for others and care about nature. They both have a solid foundation, but also a strong desire for knowledge and creativity, as well as other healthy will quality [8]. Therefore, we must make the children's physical, intellectual and language, emotion, social intercourse and aesthetic and so on in the process of physical activity. In contemporary kindergartens should strive and firmly establish the "fitness oriented, comprehensive development" of the sensory integration training curriculum values, emphasis on the action of education, the child's body and organ access to the world's experience, including the touch, manual operation, smell, jump, run, etc..Through action education to open the child's curiosity, cultivate the ability and self creativity, improve the desire for action.

Improve the scientific level of sensory integration training content. Sensory integration training content should accord with the characteristics of children's age, and the content of the training course of kindergarten and parent organization in choosing and organizing sensory integration should be arranged according to the physical and intellectual abilities of different ages, and the content of sensory integration training should be integrated with the training. Children as a whole, aesthetic, mental, emotional, language, cooperation and even communication, physical and other aspects of development are interrelated, so in the choice of sensory integration training content must take into account the child's awareness and interest, focus on the nature of life processes and casual; in addition, the content of sensory integration training content increase the proportion of physical training.

Pay attention to the safety and comprehensive of sensory integration training. When children play games, a variety of perceptual ability to be fully played, the games are a lot of learning, exercise the most effective means. Integrating sensory integration and training into the physical activities of kindergarten and parent child, can not only have the targeted treatment of sensory integration and disorder of the children, but also avoid the training content monotonous so that children lose interest. Therefore, the kindergarten and the parent child organization should pay attention to the training of the comprehensive, use the diversification of the practice method, make the sense of the function of the sense of consciousness to improve, and promote the overall development of children's organs system and the physical quality. At the same time, children's immature organ development is not yet mature, and curious, active, good imitation, and the lack of experience of life, tend to overestimate themselves, often do not contribute and judgment and action. Therefore, in order to effectively carry out sensory integration training, kindergarten and child care organizations must pay attention to the safety of the organization of sensory integration training.

Provide a good fun training environment, improve the sense of sensory integration training equipment. Sensory integration training needs a certain activity space and activity materials, training equipment of the fun and lively for children to attract attention is very important [9]. The kindergarten and family training institutions should bring to the game, so that children show great enthusiasm and attention in training, should be an instrument to create a more lively and interesting, vivid and enjoyable gameplay. Sensory integration training equipment can be combined with the 
children's sports game content: such as slide, jump table, color bag, balance ball, trampoline, also can summarize the characteristic of equipment itself, combine with the characteristics of age and game and entertainment principle, design a brilliant, fascinating game. In order to promote the children's balance, sports, skin, and other sensory and auditory and other sensory in the same time to repeat the same time, achieve the practice effect of sensory integration.

Strengthening the construction of teachers' team in sensory integration training. The construction of sensory integration training teachers directly affects the training quality and the implementation effect of the kindergarten and parent organization. The comprehensive knowledge structure, systematic teaching method, good professional ethics and other professional quality of teachers should be able to promote the development of sensory integration training course teaching. Preschool teachers should be to cultivate children's harmonious development for the purpose of sensory integration training, in order to comprehensively improve the basic quality of children as the fundamental purpose, follow the "game" and "interest" principle, "creating a multi-purpose" individual play, individual play, collective competitive game, try to make the children in a good mood actively into the training, in order to arouse children's curiosity and desire to explore the strong activity of desire, so as to improve the effect of training. In addition, teachers should do for all children in accordance with their aptitude, adhering to the "scientific" and "step by step" principle, follow the children's age characteristics and individual special needs, the scientific selection of the contents and methods of training, from easy to difficult, from simple to complex, promote each child development at different levels.

\section{Conclusion}

Sensory integration training is a kind of sports training correction method, it is through specific sports equipment for children's feeling and sports ability for purpose, plan, target training, is a kind of children are willing to participate in the sports games [10]. Sensory integration training can promote the development of children's movement, physical fitness, body coordination, attention, understanding, memory, creativity, performance, interpersonal skills, language skills, and so on. This research is based on the development and needs of children, from the creative and development of sensory integration training equipment, the effective cooperation of parents and their home, the concept and organization of kindergarten teacher education, and construct the sustainable development.

\section{Acknowledgement}

This work is supported by general subject of "the Twelfth Five-year Plan" on educational science of Liaoning province: Action Research on Sensory Integration Training Integrate into Children's Sports Activities, 2015, Approval (JG15CB167).

\section{References}

[1] Z. X. Zhu, "Child Psychology," Beijing: People's Education Press, 1981.

Baidu Encyclopedia

"Sensory integration

training," http://baike.baidu.com/link?url=JV-zZIVoFvFdYYOGaky1TpvF3vP0ulr7_Lf1bdXNKhCsOoR hg777tOzRJXHiPBI_IyIHXJ55ud2GeWUpTrKlma, 2015-10-20.

[3] Ministry of Education of the People's Republic of China, "Action plan for the revitalization of education in twenty-first Century," http://www.edu.cn/20010101/19628.shtml, 2015-10-20.

[4] Ministry of Education of the People's Republic of China, "Guidelines for the education of the kindergarten

(Trial Implementation)," http://www.moe.gov.cn/publicfiles/business/htmlfiles/moe/s3327/201001/xxgk_81984.html, 2015-10-20. 
[5] J. Y. Cai, F. S. Gao, J. Kang, "On the effect of sensory integration training on the development of young children," Success (Education), vol. 17, no. 4, pp. 88-93, 2013.

[6] J. Y. Ling, "A study on the effect of sensory integration training on the physical and mental quality of children," Education teaching research, vol. 21, no. 12, pp. 21-23, 2004.

[7] Baidu Encyclopedia, "Action Research," http://baike.baidu.com/link?url=QezZCFMBaSWKXdhvEWdX46R-5AM9003ukHD7ALDF8NctsZr5-Py1CLETJF_mVS_gpLrgmyRGjRs4J9V2MQKdq, 2015-10-20.

[8] X. Y. Ou, "Action research on the implementation of sex education in kindergarten," Master's degree of Southwestern University, 2012.

[9] D. M. Shan, "The application of sensory integration training in children's physical education," Journal of Shandong Sports Institute, vol. 16, no. 1, pp. 25-27, 2001.

[10] A. Z. Wang, H. W. Liu, Y. X. Wei, "Carry out sensory integration training, promote the comprehensive development of children," Studies in Preschool Education, vol. 32, no. 10, pp. 45-46, 2007. 